\title{
VENEZUELA (2015): UN RÉGIMEN HÍBRIDO EN CRISIS*
}

\author{
Venezuela (2015): A Hybrid Regime in Crisis
}

\author{
RAÚL A. SÁNCHEZ URRIBARRÍ \\ Universidad de La Trobe \\ Melbourne, Australia
}

\section{RESUMEN}

El 2015 fue un año muy importante en la política venezolana. Por primera vez desde que el chavismo asumió el control de los poderes públicos en el país tras la llegada de Hugo Chávez al poder en 1998, la coalición opositora Mesa de la Unidad Democrática (MUD) ha ganado las elecciones legislativas por un margen considerable sobre el oficialista Partido Socialista Unido de Venezuela (PSUV) ¿En qué contexto ocurrió un giro tan dramático en el escenario político venezolano? ¿Por qué gana la Unidad? ¿Es posible la coexistencia democrática de estos dos grupos políticos en el marco de un régimen híbrido con prácticas autoritarias tan arraigadas? El presente artículo ofrece datos relevantes para responder estas interrogantes, las cuales son claves para entender la situación actual y futuro inmediato del país.

Palabras clave: Venezuela, chavismo, elecciones, régimen híbrido, crisis.

\begin{abstract}
2015 was a very important year in Venezuelan politics. For the first time since Hugo Chavez arrived in power, and Chavismo became the country's dominant political force, the opposition coalition Unity Democratic Movement (MUD) won the legislative elections by a considerable margin over the governing United Socialist Party (PSUV). What was the context for such a dramatic sea change in Venezuelan politics? Why did the opposition win the election? Is it possible to envision these two parties coexisting within a hybrid regime with distinctive (and persistent) authoritarian traits? This article summarizes relevant information to explore these important questions, and thus assess the country's current political situation and immediate future.
\end{abstract}

Key words: Venezuela, chavismo, elections, hybrid regime, crisis.

* El presente artículo ha sido preparado para la edición 2016 del Anuario Político de la Revista de Ciencia Política del Instituto de Ciencia Política de la Pontificia Universidad Católica de Chile (Santiago de Chile). Un agradecimiento especial a la firma consultora EcoAnalítica por compartir sus informes sobre la economía venezolana en el 2015. De igual modo, agradezco a Andrea Guerrero su ayuda como asistente de investigación en el presente proyecto. Cualquier omisión o error es mi responsabilidad. 


\section{INTRODUCCIÓN}

El 2015 fue un año de grandes dificultades para Venezuela. El país continuó sumiéndose en una difícil crisis económica -la más importante en la era del chavismo y una de las más profundas que ha atravesado en su historia. Según las cifras oficiales más recientes emitidas por el Banco Central de Venezuela, el 2015 cerró con una inflación anual de 180,9\% y su Producto Interno Bruto experimentó una caída de aproximadamente 5,7\% (Banco Central de Venezuela, 2016). En estos momentos, la economía venezolana tiene el dudoso honor de ser la de peor rendimiento en la región (Al Jazeera, 2016; The Economist, 2016). El año pasado los venezolanos se enfrentaron a una realidad diaria cada vez más compleja, que afecta prácticamente a todos (y especialmente a los más pobres), y que es el elemento más importante para entender la conflictiva situación política del país. El dólar paralelo (o de mercado negro) continúa aumentando de forma vertiginosa y el precio del petróleo, a la fecha de publicación del presente artículo, continúa sin recuperarse de forma significativa. La escasez cada vez más acentuada de diversos productos, incluyendo comida, medicinas y otros artículos de la cesta básica, y la lucha diaria para obtenerlos a precios cada vez más costosos, son ahora parte de la realidad cotidiana de los venezolanos y no parecen tener pronta solución.

Estos y otros preocupantes indicadores van acompañados de reseñas periodísticas y anecdóticas que describen una creciente tensión social en el país -quizás la más intensa que ha vivido Venezuela en su historia contemporánea- la cual se evidencia en el aumento de la delincuencia, en los cada vez más numerosos conflictos sociales y laborales y en una sensación colectiva de inestabilidad y angustia por el futuro, difícil de medir, pero que se va traduciendo en distintos fenómenos, incluyendo la creciente tendencia a emigrar de un número cada vez mayor de venezolanos. Más allá de la polarización, estas dolencias las sienten tanto chavistas, como opositores. Todo ello amenaza con alterar de forma definitiva el precario equilibrio político del país, el cual se ha mantenido en ciernes tras el fallecimiento de Hugo Chávez y la llegada de Maduro al poder hace casi tres años. La percepción de una gran mayoría de venezolanos de que el gobierno es responsable de estos problemas fue, sin duda, la razón más importante del triunfo de la oposición en las elecciones legislativas del 6 de diciembre de 2015.

Como es bien sabido, en esa ocasión, la Mesa de la Unidad Democrática (MUD) -nombre oficial de la coalición que reúne a los partidos más importantes de oposición, incluyendo Primero Justicia (PJ), Acción Democrática (AD) y Voluntad Popular (VP)- obtuvo en total 112 escaños en la Asamblea Nacional, de un total de 167; es decir, más de las dos terceras (2/3) partes del Poder Legislativo. Ello constituye un hecho sin precedentes en el contexto del régimen político venezolano, el cual ha funcionado por más de una década con un control hegemónico de las distintas ramas del poder público nacional y que ha sido catalogado como un régimen político híbrido desde hace un buen tiempo. El triunfo tan contundente de la oposición era impensable hasta hace apenas unos meses, a pesar de que las encuestas tenían tiempo señalando el profundo descontento popular con el gobierno.

¿En qué consiste esta crisis? ¿Cuáles son las implicaciones más importantes del triunfo opositor para la gobernabilidad del país? ¿Es posible la coexistencia democrática 
de estos movimientos en un entorno tan polarizado, en un régimen híbrido con prácticas autoritarias tan arraigadas? ¿Estamos presenciando el "fin del chavismo" (Smilde, 2015)? En el presente ensayo propondré algunas respuestas tentativas a estas preguntas, tomando en cuenta que es una crisis en pleno desarrollo y cuyo desenlace final aún es difícil de predecir. Para ello, ofrezco primero una sinopsis de los temas más importantes de la realidad nacional venezolana en el 2015, con énfasis en la debacle económica que vive el país y en los acontecimientos políticos más notables que sirvieron de antesala a las elecciones legislativas del 6 de diciembre. Asimismo, discutiré brevemente las preguntas señaladas anteriormente, a fin de proponer algunos planteamientos que contribuyan al desarrollo de análisis empíricos sobre la realidad política venezolana actual y a la discusión de cuál será el futuro inmediato del país en estos tiempos volátiles.

\section{EL COLAPSO DE LA ECONOMÍA VENEZOLANA}

Tal y como fue reseñado en años anteriores, la realidad económica del país se ha tornado cada vez más complicada. Los indicadores fundamentales de la economía nacional muestran un gravísimo deterioro. Ya en el 2013 la economía venezolana presentaba serios problemas, con una inflación creciente y una brecha entre el dólar oficial y paralelo cada vez mayor (véase reportes de Cyr y Sagarzazu en las ediciones de 2013 y 2014 de este Anuario para los años 2012 y 2013, respectivamente). En gran medida, el deterioro de la economía venezolana derivó de la caída dramática de los precios del petróleo que ha venido ocurriendo desde finales del 2012. Esta variable es crucial para Venezuela; la economía de ese país está basada fundamentalmente en la exportación de crudo -y ahora más que nunca, gracias al declive de la exportación de otros rubros y de la producción industrial-. El barril de petróleo vendido por Petróleos de Venezuela (PDVSA) pasó, de un promedio de 95 US\$ a principios del 2014, a costar un promedio de 54 US\$ a finales del 2014 (Banco Central de Venezuela, 2016). Esta situación se agravó aún más en el 2015. Luego de haber oscilado entre 40 y 50 dólares el barril durante la mayor parte del año, el precio del petróleo se deterioró aún más y llegó a un promedio de aproximadamente 36,6 US\$ en noviembre pasado (Ecoanalítica, 2015). Hasta ahora, el precio del barril aún no se recupera del todo y, según algunos analistas, es difícil predecir cuándo lo hará (y hasta qué punto). Entre tanto, PDVSA ha respondido ante la crisis con diversas medidas dirigidas a maximizar el rendimiento de divisas por barril, incluyendo la reducción de envío de crudo a varios países de la región con los que tiene acuerdos especiales de suministro de petróleo (como es el caso de Cuba, El Nuevo Herald, 25 de marzo de 2015).

En consecuencia, el producto interno bruto (PIB) de Venezuela ha caído de forma dramática en los últimos años. Desde el 2013, la economía venezolana ha pasado del estancamiento (+1,3\% en el 2013), a sufrir un retroceso significativo en el $2014(-3,9 \%)$, y ahora más recientemente en el 2015 (-5,7\%, Banco Central de Venezuela, 2016). Estas cifras oficiales se quedan cortas según algunos observadores externos de la economía nacional (Abadi, 2015). Entretanto, la falta de confianza en el gobierno del presidente Maduro y sus políticas económicas, el discurso del Presidente (que continúa culpando 
a la "oligarquía" de las crisis), la escasez de divisas oficiales y la inestabilidad política, tuvieron como consecuencia una presión cada vez mayor en el mercado paralelo de dólares, incrementando el diferencial cambiario, ocasionando mayor inflación y, por ende, haciendo cada vez más costosa la importación de productos de todo tipo.

De ese modo, la inflación intermensual pasó de 2\% a finales del 2012 -en el período inmediatamente posterior a la última reelección de Chávez en octubre de ese año- a aproximadamente $6 \%$ intermensual a principios de 2013 (Sagarzazu, 2013, 321-322). En el 2014 esta tendencia de alta inflación se consolidó, alcanzando las cifras de 10,1\%; 16,7\%; 13,4\% y 15,7\% para los trimestres de 2014, y luego aumentando de forma dramática en el 2015. Durante ese año el Banco Central de Venezuela (BCV) dejó de emitir cifras oficiales, lo cual dio pie a todo tipo de especulaciones sobre las dimensiones del colapso económico. Finalmente, a principios del 2016, el BCV finalmente anunció que el Índice Nacional de Precios al Consumidor (INPC) en el 2015 fue de 141,5\% -cifra que el gobierno atribuyó, una vez más, a la especulación cambiaria y a la presunta guerra económica librada en su contra por el sector privado y enemigos políticos internos y foráneos (Banco Central de Venezuela, 2016).

El aumento de la inflación ha ido mano a mano con el brutal incremento del precio del dólar paralelo. Si bien en los últimos años el país ya había venido funcionando con una brecha significativa entre los precios indicados por el complicado esquema oficial de administración de divisas y el precio del dólar en el mercado negro, la situación se agravó aún más en el marco de la incertidumbre política asociada a la enfermedad y subsiguiente fallecimiento del presidente Chávez (es decir, hacia finales del 2012/principios del 2013). A la fecha, el problema cambiario constituye uno de los desafíos más difíciles para el gobierno. En los últimos 18 meses, la divisa a precio de mercado negro pasó de 100 bolívares fuertes por dólar a mediados de 2014 (Reuters, 26 de septiembre de 2014), a más de 1.000 bolívares fuertes por dólar a principios de 2016 (El País, 5 de febrero de 2016) aproximadamente cuatro veces más que la tasa oficial de cambio más alta. Por supuesto, dicho mercado negro es "ilegal" y, por ende, oficialmente innombrable; no obstante, una gran parte de la economía ha venido utilizando dicho precio como valor de referencia para una inmensa cantidad de bienes y servicios. De ese modo, el precio del dólar negro sigue siendo determinado en función del valor publicado en una página web perseguida por el gobierno (El Nuevo Herald, 23 de octubre de 2015).

Entretanto, el país ha enfrentado cada vez más problemas de abastecimiento de todo tipo de bienes y servicios, incluyendo insumos básicos para la producción agropecuaria e industrial de alimentos, medicinas, repuestos de toda clase de maquinarias y diversos bienes de consumo cotidiano. Hasta ahora esta crisis de abastecimiento continúa sin ser solucionada (Abadi, 2016). Un gran porcentaje de la opinión pública considera que la escasez de bienes y servicios es uno de los principales problemas del país, sobrepasando otras preocupaciones como la delincuencia o las tensiones políticas. La búsqueda de los bienes escasos se ha tornado en una actividad cotidiana para la inmensa mayoría de los venezolanos, sobre todo alimentos y productos de primera necesidad (Abadi, 2016). Según un análisis reciente de la reconocida firma Datanálisis, la escasez de productos 
regulados en los anaqueles de Caracas se ubica, en este momento, en aproximadamente $80 \%$ (El Nacional, 8 de abril de 2016). Con el aumento de la escasez también ha crecido el número de comerciantes informales que desea tener acceso a productos a precio preferencial, para luego revenderlos en el mercado secundario.

De igual modo, la crisis del petróleo ha colocado al gobierno en una situación muy comprometida para honrar sus compromisos financieros a nivel nacional e internacional y, sobre todo, para seguir financiando el altísimo gasto público (incluyendo los programas sociales o misiones). Hasta ahora, el gobierno ha seguido siendo buen pagador de las distintas obligaciones internacionales. No obstante, la oposición ha denunciado que estos pagos han sido efectuados a costa del sacrificio de la importación de bienes y servicios, es decir, de las necesidades de los venezolanos. Analistas nacionales e internacionales continúan monitoreando si el gobierno seguirá pagando sus compromisos financieros internacionales o si, por el contrario, incurrirá in default (véase The Economist, 2016). Entretanto, los distintos aumentos de salario mínimo no le han permitido al trabajador venezolano recuperar su poder adquisitivo, lo cual ha traído consigo un aumento acelerado de la pobreza que afecta prácticamente a todas los sectores, a excepción de aquellos que ya cuentan con recursos en moneda dura en el exterior o que tienen acceso a los mismos por vías legales o ilegales.

De igual modo, la falta de mantenimiento e inversión en la infraestructura ocasionados por la falta de recursos, la mala administración y la corrupción institucionalizada han traído consigo cada vez más problemas para el funcionamiento eficiente y consistente de los servicios públicos, incluyendo el sistema eléctrico, el suministro de agua potable, el transporte público y la salud. El problema del sistema eléctrico es, quizás, el más preocupante. En virtud del fenómeno denominado El Niño y como un virtud del mantenimiento e inversión deficientes del sistema, varias de las represas hidroeléctricas más importantes del país (incluyendo la gigantesca Central Guri) están funcionando de forma muy precaria y, según algunos, están muy cerca de colapsar. Aunque el gobierno parece estar haciendo todo lo que está a su alcance para prevenir este desenlace, la situación no deja de ser sumamente angustiante (Deutsche Welle, 2016). De igual modo, la situación del sector salud preocupa a muchos analistas. Durante el 2015 Venezuela enfrentó una epidemia del virus denominado Zika, el cual también ha hecho estragos en otras partes de la región. Sin embargo, según numerosos comentaristas, lo más preocupante del caso venezolano fue la falta de transparencia en cuanto a la existencia y magnitud de la crisis, y la ausencia notoria de medicamentos para enfrentarla (The Guardian, 28 de enero de 2016). En el contexto actual de escasez, ese mismo problema afecta la capacidad para enfrentar otras dolencias, incluyendo aquellas cuyo tratamiento requiere medicamentos e insumos importados.

\section{EL PROFUNDO DETERIORO SOCIAL}

La difícil situación económica descrita en la sección anterior ha venido acompañada de un pronunciado deterioro en materia social y, por consiguiente, un aumento en los niveles de conflictividad política. Por un lado, la delincuencia sigue siendo un problema 
grave, que cada vez enluta más hogares a lo largo del territorio nacional. En el 2015, el Reporte Anual del Observatorio venezolano de Violencia señaló que hubo casi 28.000 asesinatos, lo cual llevaría la tasa de homicidios a aproximadamente 90 por cada 100.000 habitantes y situaría a Venezuela como el país más violento del continente americano (Observatorio Venezolano de Violencia, 2015). Según esa misma organización, esta cifra refleja una tendencia alcista respecto de años anteriores, lo cual contrastaría con el resto de la región (en donde más bien la tendencia es hacia la baja o estable).

Ante esta situación, el gobierno ha respondido recientemente con medidas inspiradas en políticas de mano dura cada vez más violentas. Así, una de las noticias más importantes del 2015 fue la creación, por parte del gobierno, de unos operativos especiales denominados "Operación de Liberación y Protección del Pueblo" (OLP), desarrollados por diversas fuerzas de seguridad militares y policiales (incluyendo la Guardia Nacional, la Policía Nacional Bolivariana, y los servicios de inteligencia, Human Rights Watch, 2016). Estos operativos han sido desplegados principalmente en las zonas populares (barrios) de las urbes más importantes del país, que es donde se concentra la delincuencia organizada y en donde ocurren la mayoría de los crímenes violentos. Desde julio 2015, se han desarrollado más de 135 operaciones de este tipo, las cuales han incluido redadas y otras formas de abusos policiales, tales como robo y hurto de bienes y hasta posibles ejecuciones extrajudiciales. El gobierno sostiene que estos operativos han sido necesarios y que han ayudado a luchar contra bandas criminales y diversos grupos delictivos con presuntos nexos con grupos paramilitares colombianos y "la Derecha". De igual modo, Amnistía Internacional reportó que en el marco de las OLP, aproximadamente el $90 \%$ de las 4.000 personas detenidas durante los primeros tres meses de los operativos fueron posteriormente liberados sin cargos penales, lo cual permite suponer que una gran parte de estas "detenciones preventivas" son, en efecto, arbitrarias (Amnesty International, 2016). Sin embargo, las críticas contra las OLP no son únicamente formuladas por activistas de derechos humanos; incluso sectores vinculados al chavismo han mostrado su preocupación por estos operativos y por la posibilidad de que los abusos afecten a los sectores menos favorecidos de la sociedad (véase, por ejemplo, diversos artículos publicados en el portal Aporrea).

Asimismo, otro tema que dio mucho que hablar en el 2015 fue el deterioro del sistema penitenciario. Este también es un problema de vieja data -el sistema carcelario venezolano ha tenido una pésima reputación desde hace mucho tiempo, siendo considerado entre las más violentos de América Latina y el mundo-. Sin embargo, en los últimos años la mayor preocupación ha sido la pérdida de control de dichos centros de manos de los propios reclusos, lo cual no solo ha tenido como consecuencia la persistencia de la violencia en las cárceles, sino que, además, ha llevado a que esos recintos se consoliden como centros de distribución, organización y ejecución de delitos más allá de sus confines, con la ayuda de otras bandas o incluso de efectivos militares y policiales (véase Antillano et al., 2016). En algunos sitios las bandas de reclusos armados que los controlan son tan poderosas, que hasta tienen la oportunidad de organizar todo tipo de actividades (incluso de entretenimiento y diversión). Un ejemplo muy conocido es el un recinto penitenciario en la Isla Margarita, que hasta fecha reciente fue controlada por un recluso muy famoso 
('El Conejo'), asesinado en fecha reciente y cuya muerte fue lamentada públicamente por los reclusos con disparos al aire desde el techo de uno de los edificios principales de la cárcel, documentado en un video que dio la vuelta al mundo y que motivó numerosas críticas contra el gobierno (BBC Mundo, 2016).

El colapso de la economía venezolana también se ha visto acompañado de un creciente descontento de amplios sectores de la población, incluso de aquellos que alguna vez apoyaron al chavismo y que, hoy día, asumen una posición más crítica frente al gobierno de Maduro. Además de las consecuencias de carácter estrictamente político que se analizan en la siguiente sección, ello ha originado cada vez más acciones de calle y protestas contra el mal funcionamiento de los servicios públicos, el alto costo de la vida y la inseguridad. Estas protestas la mayoría de las veces no son de carácter masivo, pero ocurren en cada vez más lugares, y muchas veces sin planificación previa o de forma espontánea. Según reseña el Observatorio Venezolano de Conflictividad Social, durante el 2015 se contabilizaron 5.851 protestas, lo cual implica un descenso en comparación al altamente conflictivo 2014, en el que la organización contó aproximadamente 9.286 protestas (Observatorio Venezolano de Conflictividad Social, 2016). A ello se une el aumento de las huelgas y otros tipos de conflictos laborales, los cuales a menudo también involucran a empleados del sector público.

Finalmente, el aumento de la tensión social también se refleja en otros fenómenos. Por ejemplo, las "colas" para adquirir mercancías escasas muchas veces tienen que ser vigiladas o controladas por efectivos de la Guardia Nacional o funcionarios policiales. En estas colas "vigiladas" muchas veces se desarrollan incidentes violentos (sobre todo si, después de horas de espera, los comerciantes anuncian que se ha acabado la mercancía, o si la población percibe que alguien está recibiendo trato preferencial). Muchas veces estos incidentes pueden no ser catalogados como protestas, pero igual reflejan el deterioro social y la creciente frustración de la ciudadanía. Recientemente, el vicepresidente de la República, al anunciar el parte de número de accidentes de vehículos, fallecimientos y otros incidentes durante los días de asueto de Semana Santa en 2016, hizo referencia a que hubo "veintiún saqueos" en distintos lugares del país (El Nacional, 28 de marzo de 2016). De igual modo, el aumento de linchamientos preocupa enormemente a la ciudadanía. Aunque el número de estos eventos no ha sido documentado de manera oficial, el fenómeno se ha ido convirtiendo en uno de los temas más importantes en la opinión pública (Contrapunto, 2016).

Finalmente, como consecuencia del alto costo de la vida y el deterioro social, en el 2015 el tema de la emigración al exterior cobró cada vez más relevancia. Este ha sido un tema que se ha ido asomando de manera silenciosa, cobrando cada vez mayor importancia en la medida que el entorno social, económico y político del país se ha ido deteriorando. Si bien no hubo ninguna noticia particular en ese sentido, cada vez hay más conciencia de la importancia de este fenómeno (Martínez, 2015a).

\section{EL COMPLICADO ENTORNO GEOPOLÍTICO}

El gobierno también ha enfrentado importantes problemas a nivel internacional. Durante el 2015 se hizo aún más evidente el declive de Venezuela como potencia intermedia en el 
contexto latinoamericano debido, entre otros motivos, a la falta de recursos provenientes del petróleo para ayudar a otros gobiernos en la región, la falta de carisma e influencia personal del presidente Maduro en el orbe regional y la creciente percepción de que el régimen es cada vez más autoritario. Además, varios aliados tradicionales de Venezuela también confrontan importantes problemas internos (como Brasil o Chile) y, con la victoria de Mauricio Macri en Argentina, Venezuela ha perdido un aliado muy e influyente en el MERCOSUR y toda la región. Finalmente, como es bien sabido, el aliado más importante del gobierno a nivel internacional -Cuba- vive su propio proceso de cambios, sobre todo con el acercamiento entre Washington y La Habana. Aunque tales cambios no parecen haber afectado la relación entre los dos países, es lógico suponer que eventualmente será así.

Por otra parte, la relación de Venezuela con Colombia ha continuado siendo tensa. Uno de los temas más importantes en las relaciones entre ambos países es la dinámica del comercio transfronterizo, sobre todo el "contrabando de extracción" que existe en las zonas fronterizas más activas desde hace varios años (como la del estado de Táchira, ver El País, 20 de agosto de 2015), producto principalmente de la enorme diferencia de precios entre ambos países de varios productos básicos que son regulados en Venezuela y que son mucho más costosos en Colombia (incluyendo gasolina, carne, leche, azúcar y otros productos). Este comercio ilegal se da bajo el amparo de funcionarios de ambos lados de la frontera y con la intervención de diversos tipos de grupos ilegales armados. Esta delicada situación se hizo aún más difícil entre agosto y octubre de 2015, cuando se generó un fuerte impasse entre los dos gobiernos, tras un incidente relacionado con la ejecución por parte del gobierno de Venezuela de redadas policiales y militares contra el contrabando (OLPs). El gobierno de Venezuela decretó el estado de emergencia en la frontera, ordenó su cierre y deportó una gran cantidad de ciudadanos colombianos (El País, 22 de agosto de 2015 y fechas siguientes), lo cual ocasionó una gran crisis de escala internacional. Se calcula, que más de 20.000 ciudadanos colombianos huyeron de Venezuela tras el conflicto (El Nacional, 19 de septiembre de 2015). Aunque un análisis detallado de este incidente escapa de los confines del presente artículo, cabe recalcar, que en aquel entonces se especuló que la reacción del presidente Maduro era de carácter político y tenía mucho que ver con la eventual celebración de las elecciones parlamentarias y con la influencia que la declaración de estado de excepción pudiera tener en su desarrollo y resultado (Gunson, 2015).

Por otro lado, durante el 2015 el gobierno de Venezuela también tuvo serios problemas con Guyana, país con el que mantuvo relaciones muy cordiales durante el gobierno de Chávez (The New York Times, 19 de noviembre de 2015). En este caso, el conflicto está vinculado al desarrollo de la explotación de petróleo en una zona marítima disputada por Venezuela por parte de la empresa Exxon Mobil (lo cual guarda relación con un conflicto de más de un siglo sobre el territorio del Esequibo). Maduro llegó a retirar al embajador de Venezuela en Georgetown y amenazó con suspender el envío de petróleo a Guyana bajo trato preferencial (esquema que abarca a varios países del Caribe, incluyendo a Guyana). Aunque el enfrentamiento como tal ya pasó y los dos gobiernos han hecho esfuerzos importantes para solventarlo, es probable que en el 2016 haya más noticias al respecto. 


\section{EL ESCENARIO POLÍTICO Y LAS ELECCIONES PARLAMENTARIAS DE 2015}

¿Hasta qué punto la crisis ha afectado al gobierno de Maduro? Al principio, todo este rosario de dificultades no se tradujo en un deterioro inmediato de respaldo al presidente Maduro, y mucho menos en una amenaza a la estabilidad del sistema. El Presidente ha respondido afirmando que la culpa de la situación es de enemigos externos de la Revolución, del sector privado vinculado a la oposición, de la oposición misma, de quintas columnas y de otros actores llevando a cabo una guerra económica contra el gobierno. Ese fue su tono dominante en los últimos dos años y en la actualidad sigue siendo su posición frente a la crisis -a pesar de que los problemas han aumentado y que resulta claro que ese discurso no es aceptado sino por un sector minoritario de la población que los analistas consideran "chavistas duros" y que siguen apoyando al Presidente-. El gobierno de Maduro ha hecho todo lo posible por proteger de los embates de la crisis al sector socioeconómico de escasos recursos, el cual sigue siendo el que concentra la mayor cantidad de votantes y activistas a favor del oficialismo. A tales fines, ha procurado mantener intactos diversos programas sociales, incluyendo la promoción de distintas iniciativas para asegurar la distribución de alimentos y productos básicos hacia los grupos más desfavorecidos. Sin embargo, la crisis ha afectado, en mayor o menor medida, a todos los venezolanos y ello ha conllevado un marcado descenso de la popularidad del Presidente y del oficialismo como opción política.

Para finales de 2015, antes de las elecciones parlamentarias, el respaldo popular al oficialismo era sumamente bajo, sobre todo en un contexto político polarizado. Por ejemplo, según la última encuesta de Venebarómetro antes del 6 de diciembre, aproximadamente $80 \%$ de los encuestados señalaban que el país iba en la dirección equivocada, evaluación que gozaba de consenso entre los distintos estratos sociales y zonas geográficas del país. De igual modo, solo el $31 \%$ de los encuestados manifestaban ser partidarios del oficialismo y más del $60 \%$ señalaban que un triunfo del oficialismo empeoraría la situación del país (Martínez, 2015b). Por otro lado, para noviembre de 2015 la popularidad del presidente Maduro había descendido desde un 53\% de los encuestados en el primer trimestre de 2013, a apenas 39\% en el primer trimestre de 2014 y a la cifra de apenas $25 \%$ justo antes de las elecciones (Alfredo Keller y Asociados, 2015). En esa misma encuesta, aproximadamente el $73 \%$ de los encuestados señaló como culpable de la crisis a algún actor ligado al oficialismo (33\% al gobierno nacional, $25 \%$ a Maduro, $4 \%$ al Socialismo del Siglo XXI, $9 \%$ a Hugo Chávez y un 2\% al chavismo).

No obstante, a pesar de la crisis, la oposición tampoco las tuvo todas consigo para ganar la elección. Como ya han señalado varios analistas, Venezuela es gobernada por un régimen "híbrido" o semiautoritario, con instituciones democráticas sumamente débiles y una praxis autoritaria cada vez más acentuada. Este régimen se ha ido consolidando desde hace ya algún tiempo, sobre todo con posterioridad al giro abierto hacia el "Socialismo del Siglo XXI" dado por el presidente Chávez con posterioridad a su reelección en el 2006 (Álvarez, 2007; Chaguaceda, 2015; Corrales y Penfold, 2011; Corrales e Hidalgo, 2013; Corrales, 2015; Kornblith, 2013; Sánchez Urribarri, 2011, entre otros). Aunque esta 
clasificación no goza de un consenso completo (varios académicos y analistas tienen una visión menos crítica de la naturaleza del régimen político venezolano), distintas organizaciones han ido documentando y señalando esta tendencia (por ejemplo, el declive de Venezuela en los indicadores POLITY IV y de la organización Freedom House, entre otros, véase Center for Systemic Peace, 2014 y Freedom House, 2016).

Además del surgimiento y persistencia de un discurso político excluyente, los espacios de disenso y mecanismos de rendición de cuentas y control político establecidos en la Constitución y las leyes y que definen la supuesta estructura institucional democrática del país han sido minados sistemáticamente (Corrales, 2015). Por ejemplo, el funcionamiento de los medios de comunicación y el ejercicio de la libertad de expresión en Venezuela están cada vez más comprometidos. El gobierno ha ido desarrollando una estrategia de hegemonía comunicacional, que ha llevado al uso indiscriminado de transmisiones forzadas por televisión (cadenas, véase Cañizález, 2016) y a la creación de cientos de nuevos medios comunicacionales en manos del gobierno, alterando definitivamente el balance entre los medios privados independientes, y los públicos o privados con afinidad al gobierno. Esta estrategia de hegemonía comunicacional se ha extendido a la prensa escrita (incluyendo la creación de varios periódicos oficiales de amplia distribución); y un número cada vez mayor de canales de televisión y estaciones de radio, incluyendo algunas denominadas comunitarias que son supuestamente independientes pero que, con frecuencia, terminan siguiendo las pautas establecidas por el gobierno (Corrales, 2015). De igual modo, el Poder Judicial ha sido progresivamente sometido al gobierno, desde el Tribunal Supremo hasta los tribunales de instancia (Brewer Carias, 2015; Sánchez Urribarri, 2011), lo cual en los últimos años ha empeorado, en la medida que los procesos judiciales son utilizados como mecanismo de control y represión (Canova González y otros, 2015; Freedom House, 2016; Sánchez Urribarri, 2016). Este entorno político crea condiciones sumamente desfavorables para que la oposición compita en justa lid.

La oposición tuvo que esquivar diversos escollos durante la campaña electoral, el día de las elecciones, e incluso con posterioridad al anuncio oficial de los resultados (IDEA, 2015; International Crisis Group, 2015). El 22 de junio de 2015 la presidenta del Consejo Nacional Electoral (CNE), Tibisay Lucena, hizo la convocatoria oficial de las elecciones parlamentarias 2015 (\#MonitorProDaVinci, 22 de junio de 2015). Antes del comienzo oficial de la campaña, la oposición tuvo que resolver fuertes problemas internos para la escogencia de sus candidatos para la Asamblea Nacional; sortear diversas trabas institucionales y bregar con la falta de transparencia en el funcionamiento del Estado y las instituciones públicas -incluyendo el CNE-. Formalmente, según el cronograma del CNE la campaña solo debía durar cuatro semanas -desde el 13 de noviembre de 2015 hasta el 3 de diciembre de 2015. Si bien ello estaría bien en un contexto democrático medianamente funcional, en el caso de Venezuela eso crea graves desventajas, habida cuenta de la desconfianza existente respecto de miembros del CNE y otros entes institucionales. En efecto, hubo varias decisiones controversiales del máximo organismo electoral. Ello incluyó la adopción 
sobrevenida, el 25 de junio de 2015, con posterioridad a la realización de las primarias para la Unidad y el Partido Socialista Unido de Venezuela (PSUV), del criterio de paridad y alternabilidad de género para las elecciones parlamentarias de 2015. De igual modo, el CNE y posteriores decisiones judiciales impidieron la participación del grupo disidente del chavismo Marea Socialista y, por otro, afectó la participación de varios partidos opositores (El Universal, 16 de Mayo de 2015). En todo caso, el mayor problema continuó siendo la impunidad con la que actúa el régimen para promocionar sus candidatos con el uso de recursos públicos, haciendo caso omiso a la normativa en la materia, incluyendo el uso indiscriminado de cadenas (como fue indicado anteriormente) y la falta de sanciones contundentes sobre el particular por parte del CNE. Finalmente, otro punto que hay que recalcar es la negativa del gobierno a invitar observadores internacionales. La única misión internacional importante fue la de UNASUR, liderada por el expresidente dominicano Leonel Fernández, la cual enfrentó diversos contratiempos (Proyecto Integridad Electoral Venezuela, 2015) y que no dejó de ser controversial (Perina, 2015).

Durante la precampaña y la campaña ocurrieron una serie de incidentes que caldearon los ánimos de ambos lados del espectro político. Por una parte, el dirigente opositor del Partido Voluntad Popular (VP), Leopoldo López, uno de los líderes más importantes del movimiento opositor, fue condenado a casi catorce años de presidio por una serie de presuntos delitos relacionados con su participación en las protestas de principios de 2014 (conocidos como La Salida, véase \#MonitorProDaVinci, 11 de septiembre de 2015). El juicio y la decisión judicial en cuestión han sido duramente condenados por diversos actores políticos nacionales e internacionales. Además, el problema de los presos políticos sobre todo tras La Salida ha alcanzado notoriedad internacional. Todo ello ha contribuido, sin duda, a reforzar la creciente percepción de que el régimen está haciéndose más autoritario (Freedom House, 2015). De igual modo, durante esta etapa la retórica oficialista se tornó amenazante, poniendo en tela de juicio la viabilidad de los resultados electorales. Ya antes del comienzo de la campaña Maduro llegó a afirmar que si ganaba la oposición no entregaría la revolución, y que gobernaría en alianza con el pueblo y el Ejército (Diario Clarín, 30 de octubre de 2015). En plena campaña Maduro sostuvo que el PSUV lograría la victoria a como diera lugar, que si ganaba la oposición el país se volvería un caos y que la revolución no iba a capitular. Afortunadamente, la agresividad del entorno político no condujo a situaciones masivas de violencia política de ninguno de los dos lados. Hubo algunos incidentes lamentables -por ejemplo, el asesinato del dirigente opositor Luis Díaz el 25 de noviembre de 2016- pero, en general, la campaña fue menos violenta de lo que se llegó a temer (International Crisis Group, 2015).

\section{Resultados Electorales}

En todo caso, a pesar de los problemas señalados, el 6 de diciembre no ocurrieron mayores incidentes a lo largo del territorio nacional, a excepción de la prórroga de votación hacia el final de la jornada electoral decidida unilateralmente por el CNE y que fue rechazada en su momento por los partidos de oposición). Así, según los resultados oficiales anunciados 
por el CNE, la elección tuvo una participación de aproximadamente 74\% del padrón electoral, es decir, un total de 14.385.439 votos (CNE, 2015, véase también Martínez, 2015c). De esa suma, hubo 13.699.230 votos válidos, es decir, que el total de votos nulos fue casi 700.000 (aproximadamente 5\%). Así, de un total de 167 diputados (CNE, 2015), 112 diputados fueron adjudicados al movimiento opositor Unidad Democrática (MUD), es decir, más de las 2/3 partes de la Asamblea, lo cual incluye 81 nominales, 28 por lista y 3 indígenas; mientras que 32 nominales y 23 por listas fueron adjudicados al partido oficialista PSUV (El Universal, 8 de diciembre de 2015). La oposición ganó en todos los estados, menos en cinco estados tradicionalmente chavistas (Apure, Cojedes, Delta Amacuro, Guárico y Yaracuy); y llegó a triunfar en circunscripciones que tradicionalmente habían sido bastiones del chavismo. Estos 112 escaños le permiten teóricamente a la oposición gozar de mayoría calificada en el Parlamento, lo cual, según la Constitución de la República, le faculta para ejercer toda una serie de poderes políticos, incluyendo la modificación de leyes orgánicas y la iniciativa de convocar a una Asamblea Nacional Constituyente (García Soto, 2015).

Como era de esperarse, desde entonces la situación política desde entonces ha sido muy tensa. Durante el período previo a la instalación de la Asamblea Nacional (en 5 de enero de 2016), el gobierno comenzó a mostrar muy poca voluntad de coexistir con la oposición. Durante ese largo mes, el Tribunal Supremo de Justicia suspendió la proclamación de tres diputados opositores (y uno chavista) por presuntas irregularidades en la elección (decisión que eventualmente fue dejada sin efecto, pero que entretanto puso en entredicho la mayoría calificada de la oposición en el Parlamento); el expresidente de la Asamblea Nacional, Diosdado Cabello, instaló un denominado "Parlamento Comunal", "que le permite al pueblo disponer de recursos, jefaturas, toma de decisiones, leyes, y que le permita al pueblo disponer su forma de vida" (BBC, 15 de diciembre de 2015); y, de igual modo, procedió a designar 13 magistrados del Tribunal Supremo de Justicia principales y 21 suplentes, designación que le permitió a diversas facciones del oficialismo prolongar su control e influencia en el Máximo Tribunal más allá de la toma de posesión de la nueva Asamblea Nacional. Esta designación fue considerada inconstitucional e ilegítima por la oposición y constituye un importante punto de inflexión en la consolidación del autoritarismo en Venezuela.

\section{CONCLUSIONES}

En el presente trabajo he procurado resumir los aspectos más importantes del acontecer político venezolano durante el 2015 (incluyendo unos breves comentarios relativos al año que cursa). Como he explicado anteriormente, la única forma de entender el giro tan dramático que constituye el triunfo de la unidad democrática en las elecciones parlamentarias de finales del 2015 consiste en entender el contexto social, político y económico adverso que el presidente Maduro ha enfrentado en los últimos dos años. Si tomamos en cuenta la magnitud de la crisis económica y el creciente deterioro social, es mucho más fácil entender por qué la oposición obtuvo un triunfo tan contundente 
en las elecciones de representantes a la Asamblea Nacional del 6 de diciembre de 2015. Dicho contexto no solo ha obedecido a factores exógenos -especialmente el descenso del precio del petróleo- sino que también ha derivado de la esclerosis del discurso político de Maduro (anclado a la estructura populista descrita por varios estudiosos del caso venezolano, por ejemplo Hawkins, 2010). De igual modo, Maduro pareciera estar preso, no solo de su propio discurso, sino además de élites políticas y económicas poderosas que se benefician del equilibrio negativo en el que se encuentra el país, lo cual trae consigo notoria frustración en el seno del chavismo, especialmente a nivel de los movimientos sociales y líderes comunitarios.

Sin embargo, a pesar de la debacle económica del país y del triunfo contundente de la oposición en las elecciones parlamentarias, todavía no podemos ser optimistas respecto del año en curso. En lo que va del 2016, el régimen ha mostrado una profunda resistencia al cambio y ha tenido muy poca disposición a coexistir con la Asamblea Nacional en manos de la oposición. Ante la pérdida de control del Poder Legislativo, el régimen ha pasado a bloquear de forma manifiesta cualquier iniciativa política significativa promovida por la asamblea a través de la Sala Constitucional del Tribunal Supremo de Justicia. Como indicamos anteriormente, el Tribunal funciona como un actor de veto leal al régimen y del que no se espera otra cosa que fallos a favor del gobierno, más allá de la naturaleza jurídica de la petición en concreto. Por supuesto esto no quiere decir que la normativa constitucional y legal aplicable a estos casos "megapolíticos" sea enteramente irrelevante desde un punto de vista estrictamente jurídico. La dimensión legal de la confrontación política no deja de existir en varios casos, así sea de forma muy precaria desde el punto de vista argumentativo. Lo que pasa es que estamos en presencia de un Tribunal prácticamente sin independencia judicial de facto, con muy poca legitimidad como árbitro imparcial, tanto ante las demás élites políticas como la opinión pública nacional e internacional. Así, en lo que parece ser el nuevo equilibrio político surgido tras la llegada a la asamblea de la oposición, el régimen pareciera estar decidido a gobernar soslayando y bloqueando al máximo ente legislativo en la medida de lo posible, aun a través de actuaciones evidentemente politizadas y antijurídicas por parte del máximo tribunal. Esta situación no va a ser definitiva pero, por ahora, es una de las características más importantes del régimen híbrido venezolano.

Por otro lado, desde que el nuevo Parlamento se instaló en el poder, y en la medida en que el régimen fue entorpeciendo su actividad, la agenda legislativa de la oposición ha sido cada vez más desafiante contra el régimen. En fecha reciente, el Parlamento sancionó la Ley de Amnistía y Reconciliación, cuya ejecución hubiera implicado la libertad de importantes líderes opositores, incluyendo Leopoldo López. Como era de esperarse, esta ley fue declarada inconstitucional por la Sala Constitucional (El País, 12 de abril de 2016). Ahora, la oposición está dedicada a sopesar el mérito de distintos tipos de procesos refrendarios establecidos en la Constitución para remover al presidente Maduro del poder, incluyendo la posibilidad de un referéndum revocatorio. Las encuestas más recientes indican que al menos más del 50\% del electorado estaría de acuerdo en revocarle 
el mandato al presidente Maduro y más del $63 \%$ de los encuestados está de acuerdo con que el Presidente deje el poder este año (Panorama, 26 de marzo de 2016. Sin embargo, es difícil asegurar que esto va a ocurrir (y, lo más importante, cómo y cuándo).

Entre tanto, ante ese escenario polarizado y de abierta confrontación y habida cuenta de la recuperación muy limitada de los precios del petróleo, la crisis económica del país parece que va a continuar en los próximos meses, e incluso agravarse aún más. En un reporte reciente, el Fondo Monetario Internacional predijo que el país empezaría a vivir un período hiperinflacionario, con una inflación anual para el 2017 pronosticada en más de $2.000 \%$. Un escenario tan dantesco hace aún más difícil predecir qué va a pasar en los próximos meses. Aunque es difícil ser optimistas, los venezolanos han seguido respaldando la vía electoral como mecanismo para resolver sus diferencias. El gobierno de Maduro reconoció pacíficamente su derrota y, a pesar de su politización pública y notoria, las Fuerzas Armadas hasta ahora no han protagonizado episodios violentos a favor de uno u otro bando. Así, a pesar del creciente autoritarismo en Venezuela, hay esperanza de que las instituciones electorales del régimen permitan un desenlace constitucional y pacífico del conflicto.

\section{REFERENCIAS}

Abadi, Anabella. 2015. “Economía 2015: Estimaciones y Especulaciones" (1 de diciembre). En: http:// prodavinci.com/blogs/economia-2015-estimaciones-y-especulaciones-por-anabella-abadi/.

2016. "Qué ha hecho el Gobierno para Aliviar las Colas?" (21 de marzo). En: http:/ / prodavinci. com/blogs/que-ha-hecho-el-gobierno-para-aliviar-las-colas-por-anabella-abadi/.

Al Jazeera. 2016. "Venezuela: The World's Worst Performing Economy". En: http:/ /www.aljazeera.com/ programmes/countingthecost/2016/02/venezuela-world-worst-performing-economy-160227103201996. html.

Alfredo Keller y Asociados. 2015. "Estudio de la Opinión Pública Nacional. 4 Trimestre de 2015".

Álvarez, Ángel E. 2007. “Venezuela 2007: Los Motores del Socialismo se Alimentan con Petróleo”. Revista de Ciencia Política 27 (Esp): 265-289.

Amnesty International. 2016. "Annual Report: Venezuela 2015/2016". En: https://www.amnesty.org/ en/countries/americas/venezuela/report-venezuela/.

Antillano, Andrés, Pojomovsky Iván, Zubillaga Verónica, Sepúlveda, Chelina y Hanson Rebecca. 2016. "The Venezuelan Prison: From Neoliberalism to the Bolivarian Revolution". Crime, Law, and Social Change 65: 195-211.

Banco Central de Venezuela. 2016. “Resultados del Índice Nacional de Precios al Consumidor, Producto Interno Bruto y Balanza de Pagos. Cuarto Trimestre de 2015-Cierre del Año 2015". [En línea] http:// www.bcv.org.ve/Upload/Comunicados/aviso180216.pdf.

BBC Mundo. "Quién Era el Conejo, el Homenajeado con Disparos al Aire en una Cárcel de Venezuela?" (29 de enero). En: http://www.bbc.com/mundo/noticias/2016/01/160129_conejo_alias_carcel_ venezuela_armas_prision_amv.

Canova González, Antonio; Luis A. Herrera Orellana, Rosa E. Rodríguez Ortega, Giuseppe Graterol Stefanelli y Ana Carola Fernández. 2015. El TSJ al Servicio de la Revolución. Caracas: Editorial Galipán.

Cañizález, Andrés. 2016. "Las 500 Horas de Maduro en Cadena". En: http:/ /monitoreociudadano.org/ yomonitoreo/2016/01/4903/.

Center for Systemic Peace. 2014. The Polity Project. En: http:/ / www.systemicpeace.org/polityproject.html 
Chaguaceda, Armando. 2015. “'Quo Vadis Venezuela': De la Democracia Delegativa al Autoritarismo del Siglo XXI". Revista Mexicana de Análisis Político y Administración Pública 4 (1): 175-202.

CNE. 2015. Elecciones a la Asamblea Nacional 2015 (6 de diciembre). En: http:/ / www.cne.gob.ve/resultado_ asamblea2015/r/0/reg_000000.html.

Contrapunto. 2016. “Linchamientos. Justicia Popular o Asesinato Grupal?". En: http://www.contrapunto. com/noticia/la-metastasis-de-un-cancer-social-el-linchamiento-70816/.

Corrales, Javier. 2015. "Autocratic Legalism in Venezuela". Journal of Democracy 26 (2): 37-51.

Corrales, Javier y Michael Penfold. 2011. Dragon in the Tropics: Hugo Chávez and the Political Economy of Revolution in Venezuela. Washington, DC: Brookings Institution Press.

Corrales, Javier y Manuel Hidalgo. 2013. "El Régimen Híbrido de Hugo Chávez en Transición (20092013)". Desafíos 25 (1): 45-84.

Cyr, Jennifer. 2013. “Que Veinte Años no es Nada: Hugo Chávez, las Elecciones de 2012 y el Continuismo Político Venezolano". Revista de Ciencia Política 33 (1): 375-391.

Deutsche Welle. 2016. “Venezuela: No Todos Quieren Descansar los Viernes". En: http:/ /www.dw.com/ es/venezuela-no-todos-quieren-descansar-los-viernes/a-19172768.

Diario Clarín. 2015. "Maduro Amenaza con un Golpe Militar si Pierde las Elecciones" (30 de octubre). En: http://www.clarin.com/mundo/Nicolas_Maduro-Venezuela-elecciones_del_6_de_diciembreunion_civico_militar_0_1458454530.html.

Ecoanalítica. 2015. "Venezuela: Caught Between Scepticism and Uncertainty". Ecoanalítica's Perspective Report 11 (4).

El Nacional. 2015. "Así se ha Vivido un Mes de Crisis entre Venezuela y Colombia" (19 de septiembre). En: http://www.el-nacional.com/regiones/mes-crisis-Venezuela-Colombia_0_704329818.html.

. "Aristóbulo Istúriz Informó que Hubo 21 Saqueos durante Semana Santa" (28 de marzo). En: http://www.el-nacional.com/politica/Aristobulo-Isturiz-informo-Semana-Santa_0_819518131.html.

El Nuevo Herald. 2015. "Venezuela Recorta a la Mitad la Asistencia Petrolera a Cuba y el Caribe" (25 de marzo). En: http://www.elnuevoherald.com/noticias/mundo/america-latina/venezuela-es/ article16310159.html.

. 2015. “Venezuela demanda a 'Dólar Today', sitio web del dólar negro" (23 de octubre). En: http:// www.elnuevoherald.com/noticias/mundo/america-latina/venezuela-es/article41243667.html.

El País. 2016. "El Supremo de Venezuela declara inconstitucional la Ley de Amnistía y Reconciliación" (12 de abril). En: http://internacional.elpais.com/internacional/2016/04/12/america/1460414847_775907.html.

. 2016. "El Dólar Paralelo se Dispara en Venezuela" (5 de febrero). En: http://internacional.elpais. com/internacional/2016/02/03/america/1454533918_502436.html.

. 2015. "Venezuela Cierra su Frontera con Colombia tras un Ataque a Militares" (20 de agosto). En: http://internacional.elpais.com/internacional/2015/08/20/actualidad/1440046617_105035.html.

2015. "Venezuela declara Estado de Excepción en la Frontera con Colombia" (22 de agosto). En: http://internacional.elpais.com/internacional/2015/08/22/actualidad/1440213301_872512.html.

El Universal. 2015. "CNE Niega a Vente Venezuela y Marea Socialista Inscribirse como Partidos" (16 de mayo). En: http://www.eluniversal.com/noticias/politica/cne-niega-vente -venezuela-marea-socialista-inscribirse-como-partidos_63406.

.2015. “Mesa de la Unidad alcanza 112 diputados en la Asamblea Nacional” (8 de 08 diciembre). En:http:// www.eluniversal.com/noticias/politica/mesa-unidad-alcanza-112-diputados-asamblea-nacional_15382.

Freedom House. 2015. “Venezuelan Court Convicts, Imprisons Opposition Leader Lopez”. En: https:/ / freedomhouse.org/article/venezuelan-court-convicts-imprisons-opposition-leader-lopez.

.2016. Anxious Dictators, Wavering Democracies. En: https://freedomhouse.org/report/freedom-world/ freedom-world-2016.

García Soto, Carlos. 2015. “Qué Puede Hacer Quien Obtenga la Mayoría en la Asamblea Nacional?” ProDaVinci (26 de febrero).

Gunson, Phil. 2015. "Elecciones Parlamentarias en Venezuela 2015: Unos Dados Cargados". Crisis Group. En: http://blog.crisisgroup.org/latin-america/venezuela/2015/11/26/elecciones -parlamentarias-en-venezuela-2015-unos-dados-cargados/. 
Hawkins, Kirk. 2010. Venezuela's Chavismo and Populism in Comparative Perspective. New York: Cambridge University Press.

Human Rights Watch. 2016. "Poder sin Límites: Redadas Policiales y Militares en Comunidades Populares y de Inmigrantes en Venezuela". En: https:/ /www.hrw.org/es/report/2016/04/04/poder-sin-limites/ redadas-policiales-y-militares-en-comunidades-populares-y-de.

International Crisis Group. 2015. "Fin de la Hegemonía: ¿Qué sigue para Venezuela?" Crisis Group Informe Breve sobre América Latina 34 En: http://www.crisisgroup.org/ /media/Files/latin-america/ venezuela/b034-the-end-of-hegemony-what-next-for-venezuela-spanish.pdf.

Kornblith, Miriam. 2013. “Chavismo After Chávez?" Journal of Democracy 24 (3): 47-59.

Martínez, Eugenio G. 2015a. "5 datos importantes: ¿los venezolanos tienen intenciones de irse del país?" ProDaVinci (17 de agosto). En: http://prodavinci.com/blogs/los-venezolanos-tienen -intenciones-de-irse-del-pais-por-eugenio-martinez/.

2015b. “Análisis de la Última Encuesta de Venebarómetro antes del \#6D”. En: http:/ / prodavinci. com/blogs/analisis-de-la-utlima-encuesta-de-venebarometro-antes-del-6d-por-eugenio-g-martinez/

. 2015c. "7 Claves para Entender Qué Pasó en las Elecciones Parlamentarias del \#6D". ProDaVinci (10 de diciembre). En: http://prodavinci.com/blogs/7-claves-para-entender -que-paso-en-las-elecciones-parlamentarias-del-6d-por-eugenio-g-martinez/.

Observatorio Venezolano de Violencia. En: http://images.eluniversal.com/2015/12/28/informe-delobservatorio-venez.pdf.

Observatorio Venezolano de Conflictividad Social (2016). "Conflictividad Social en Venezuela 2015". En: http:/ / www.observatoriodeconflictos.org.ve/reporte-anual-de-la-protesta-social-en-venezuela/ conflictividad-social-en-venezuela-en-2015.

Obuchi, Richard. 2010. “Los Números del Voto Popular”. ProDaVinci (3 de octubre). En: http:/ /prodavinci. com/2010/10/03/actualidad/los-numeros-del-voto-popular/.

Panorama. 2016. “Datanálisis: El 63,6\% de los Venezolanos dice que Maduro Debería Dejar el Poder". En: http://www.panorama.com.ve/politicayeconomia/Datanalisis-El-636-de-los-venezolanos-dice-queMaduro-deberia-dejar-el-poder-20160326-0042.html.

Perina, Rubén. 2015. “¿Observación Electoral en Venezuela?” El País (30 de junio). En: http://internacional. elpais.com/internacional/2015/06/30/actualidad/1435618206_812305.html.

Proyecto Integridad Electoral Venezuela. 2015. "Reporte Especial Número 14" (julio). En: https:// politikaucab.files.wordpress.com/2015/07/boletc3adn-14-preview-1.pdf.

Reuters, 26 de septiembre de 2014. En: http://www.reuters.com/article us-venezuela-currency-id USKCN0HL2GW20140926.

Sánchez Urribarrí, Raúl. 2011. “Courts between Democracy and Hybrid Authoritarianism: Evidence from the Venezuelan Supreme Court". Law and Social Inquiry 36 (4): 854-884.

2016. "Constitutional Courts in the Region: Between Power and Submissiveness". En Comparative Constitutional Law in Latin America, editado por Rosalind Dixon y Tom Ginsburg. Edward Elgar (en prensa).

Smilde, David. 2015. "The End of Chavismo?" Current History (February): 49-55.

The Economist. 2016. "Venezuela: A Nation in a State". En: http://www.economist.com/blogs/ graphicdetail/2016/02/graphics-political-and-economic-guide-venezuela.

The Guardian. 2016. "Epidemic Fears Prompt Venezuela Doctors to Demand Zika Virus Statistics" (28 de enero). En: http://www.theguardian.com/world/2016/jan/27/venezuela-doctors -public-statistics-zika-virus-epidemic-fears.

The New York Times. 2015. "In Guyana, a Land Dispute with Venezuela Escalate over Oil". En: http:/ / www.nytimes.com/2015/11/19/world/americas/in-guyana-a-land-dispute-with-venezuelaescalates-over-oil.html?_r=0.

\#MonitorProDaVinci. 2015. “¿Qué Dijo Tibisay Lucena en la Rueda de Prensa donde el CNE Anunció la Fecha de las Legislativas?" ProDaVinci (22 de junio). En: http://prodavinci.com/2015/06/22/ actualidad/que-dijo-tibisay-lucena-en-la-rueda-de-prensa-donde-el-cne-anuncio-la-fecha-de-laselecciones-legislativas/. 
2015. "7 Claves sobre la Sentencia contra Leopoldo López". ProDaVinci (11 de septiembre). En: http://prodavinci.com/2015/09/11/actualidad/ 7-claves-sobre-la-sentencia-contra -leopoldo-lopez-monitorprodavinci/.

. 2015. "Así Se Han Desarrollado las Elecciones Legislativas del \#6D en Venezuela". ProDaVinci (6 de diciembre). En: http://prodavinci.com/2015/12/06/actualidad/asi-se-han-desarrollado -las-elecciones-legislativas-del-6d-en-venezuela-monitorprodavinci/.

Raúl A. Sánchez Urribarrí es profesor de Estudios Socio-Jurídicos en el Departamento de Ciencias Sociales en la Universidad de La Trobe Melbourne, Australia. E-mail: r.sanchezu@latrobe.edu.au. 
